\title{
Effect of valproic acid on oxidative stress parameters of glutamate-induced excitotoxicity in SH-SY5Y cells
}

\author{
BERNA TERZİOĞLU BEBİTOĞLU, ELİF OĞUZ and GÖKÇE ACET \\ Department of Medical Pharmacology, İstanbul Medeniyet University School of Medicine, İstanbul 34700, Turkey
}

Received July 10, 2019; Accepted January 30, 2020

DOI: $10.3892 /$ etm.2020.8802

\begin{abstract}
Glutamate-induced excitotoxicity has been reported to be involved in the pathophysiology of neurodegenerative disorders. It has been proposed that valproic acid (VPA), which is used in epileptic and bipolar disorders, may be protective against excitotoxic insult. The aim of the present study was to investigate the effects of VPA against the glutamate excitotoxicity in the SH-SY5Y human neuroblastoma cell line and determine its anti-oxidant capacity by measuring oxidative and anti-oxidant biochemical parameters. SH-SY5Y human neuroblastoma cells were pre-treated with 1,5 or $10 \mathrm{mM}$ VPA prior to exposure to $15 \mathrm{mM}$ glutamate. The MTT assay was performed to determine cell viability. To detect oxidative insult in glutamate toxicity and the potential anti-oxidant effect of VPA, the cell catalase (CAT), superoxide dismutase (SOD), malondialdehyde and hydrogen peroxide $\left(\mathrm{H}_{2} \mathrm{O}_{2}\right)$ activity was determined. A progressive decline in cell viability was observed with increasing glutamate concentrations $(1-50 \mathrm{mM})$. Treatment with $1 \mathrm{mM}$ VPA was revealed to be effective in increasing the viability of cells exposed to glutamate for $24 \mathrm{~h}$. Oxidative damage, including an increase in $\mathrm{H}_{2} \mathrm{O}_{2}$ and MDA, was observed in SH-SY5Y cells treated with glutamate and was reduced by pre-treatment with VPA. CAT activity was decreased following glutamate exposure, but VPA did not prevent this decrease. SOD activity was increased by treatment with VPA alone and was not affected by glutamate exposure. Overall, the present results confirmed the critical role of oxidative stress in glutamate-induced excitotoxicity. They also suggested that VPA may exert an anti-oxidant effect against glutamate-induced excitotoxicity by decreasing oxidative parameters, including $\mathrm{H}_{2} \mathrm{O}_{2}$ and MDA, but only had a slight effect on CAT and SOD activity, which have an anti-oxidant capacity.
\end{abstract}

Correspondence to: Dr Berna Terzioğlu Bebitoğlu, Department of Medical Pharmacology, İstanbul Medeniyet University School of Medicine, Ünalan mah Ünalan cad. Kuzey Yerleskesi D Blok, Üsküdar, İstanbul 34700, Turkey

E-mail: bernaterzioglu@gmail.com

Key words: valproic acid, glutamate excitotoxicity, SH-SY5Y, oxidative stress parameter

\section{Introduction}

The excitatory neurotransmitter glutamate is involved in the pathophysiology of certain neurological disorders, as well as in neuron loss, by increasing cell component damage, including mitochondrial dysfunction (1). Glutamate excitotoxicity is also considered a major mechanism underlying neuronal death, leading to neurodegeneration, as occurring in hypoxia, ischemia, traumas and chronic neurodegenerative disorders (2). It has been indicated that glutamate mediates excitotoxicity in primary cultured neurons by stimulating the N-methyl-d-aspartate receptor, which leads to increased calcium permeability and formation of reactive oxygen species (ROS), and the release of lysosomal enzymes $(3,4)$. Oxidative stress is known to be involved in several human neuropathologies, including acute hypoxia-ischemia/reperfusion and chronic neurodegenerative disorders, e.g. Parkinson's and Alzheimer's diseases $(5,6)$. Following acute glutamate administration, increased intracellular ROS accumulation, $\mathrm{Ca}^{+2}$ levels, production of peroxynitrite and depletion of glutathione were observed in the cerebral cortex of rats (7). ROS generation is involved in the pathophysiology of several neuropsychiatric disorders, since $20 \%$ of the total amount of oxygen in the body is metabolized by the brain, and the brain has a limited anti-oxidant capacity $(8,9)$. High levels of extracellular glutamate, resulting in glutathione depletion and cell injury, in addition to the inhibition of glutamate toxicity by several anti-oxidants, including $\alpha$-tocopherol and superoxide dismutase (SOD), indicate oxidative glutamate toxicity. Cultured cortical neurons from mice overexpressing the free radical-scavenging enzyme SOD were indicated to be resistant to glutamate toxicity and the involvement of glutathione in neuro-degeneration was demonstrated $(10,11)$. Excitotoxic neuronal injury is linked to the generation of free radicals and glutathione is involved in neurodegeneration $(10,11)$. It has also been speculated that the principal function of ascorbate and $\alpha$-tocopherol as anti-oxidants may be based on a synergistic effect with glutathione in the central nervous system $(10,11)$.

Valproic acid (VPA), widely used as an anti-convulsant agent and efficient mood stabilizer, has been reported to have a utility in the treatment of excitotoxicity in the hippocampus (12). The neuroprotective effect and anti-oxidant activity of VPA were studied in primary cultured rat cerebral cortical cells and chronic VPA treatment was suggested to inhibit glutamate-induced cell death, DNA fragmentation, 
intracellular free calcium imbalance, lipid peroxidation and protein oxidation (13). VPA directly inhibits histone deacetylase (HDAC), causing histone hyperacetylation and heat shock protein (HSP) induction, where HSP induction is correlated with damage resistance. VPA was indicated to exert a neuroprotective effect through these mechanisms in the cerebral ischemia model (14), it was also indicated that VPA has neuroprotective effects against brain ischemia due to its anti-inflammatory and anti-oxidant activities, as well as against HDAC and glycogen synthase kinase 3 (GSK3) inhibition $(15,16)$.

In the present study, the neuroprotective effect of VPA against oxidative glutamate toxicity was studied in the SH-SY5Y cell line, which is frequently used as a model for the study of oxidative stress associated with neuronal death and its anti-oxidant capacity, by measuring oxidative and anti-oxidant biochemical parameters.

\section{Materials and methods}

Cell culture. The study was performed using SH-SY5Y human neuroblastoma cells originally obtained from the American Type Culture Collection and kindly supplied by Dr İbrahim Akalın (Department of Medical Genetics, İstanbul Medeniyet University, İstanbul, Turkey). Every effort was made for the cell lines to be kept pure and free from contamination in the laboratory. The preventions were taken to avoid contamination; the sampling area, incubator and water bath was kept clean, the laboratory enviroment was sanitized, the biological safety cabinet was used for all procedures, all cell culture equipment, including reagents and media were sterile, antibiotics were included and sterile water was used to prevent contamination.

The SH-SY5Y cells were grown in Dulbecco's modified Eagle's medium (Thermo Fisher Scientific, Inc.) containing $10 \%$ fetal bovine serum (Thermo Fisher Scientific, Inc.), penicillin $(100 \mathrm{unit} / \mathrm{ml})$ and streptomycin $(100 \mu \mathrm{g} / \mathrm{ml})$. The cells were incubated at $37^{\circ} \mathrm{C}$ with $5 \% \mathrm{CO}_{2}$. SH-SY5Y cells were seeded into 96 -well plates ( $1 \times 10^{4}$ cells/well). To investigate the effects of L-glutamate and VPA, SH-SY5Y cells were incubated in complete culture medium for $24 \mathrm{~h}$ prior to the addition of L-glutamate or VPA.

Drug concentrations. Cells were treated with 9 different concentrations of glutamate $(1,5,10,15,20,25,30$, 40 and $50 \mathrm{mM}$; L-glutamate; cat. no. G1251; Sigma-Aldrich; Merck KGaA) to determine the glutamate toxicity in the cultured SH-SY5Y cells. The glutamate concentrations that caused a significant reduction in cell viability were determined by drawing dose-cell viability curves. The glutamate concentration of $15 \mathrm{mM}$ that caused a $20 \%$ decrease in cell viability after $24 \mathrm{~h}$ was then used for subsequent experiments. The cells were challenged with this concentration calculated from the dose-response experiment for 2 different time intervals ( 3 and $24 \mathrm{~h}$ ). Cell viability was determined by MTT assays, as described below.

SH-SY5Y cells were treated with 1, 5 and $10 \mathrm{mM}$ VPA (Depakin $400 \mathrm{mg} / 4 \mathrm{ml}$; lyophilized powder; Sanofi S.A.) for $2 \mathrm{~h}$ prior to exposure to $15 \mathrm{mM}$ glutamate. The effect of VPA treatment was tested following 2 different time intervals (3 and $24 \mathrm{~h}$ ).
Cell viability assay. An MTT (Thermo Fisher Scientific, Inc.) assay was used to evaluate cell viability. After adding MTT solution $(5 \mathrm{mg} / \mathrm{ml})$ to each well, cells were incubated for $3 \mathrm{~h}$ with $5 \% \mathrm{CO}_{2}$ at $37^{\circ} \mathrm{C}$. Following the removal of the culture medium, $200 \mu 1$ dimethyl sulfoxide was used to dissolve the formazan product. Absorbance values were measured at $560 \mathrm{~nm}$ using a microplate reader (Multiskan ${ }^{\mathrm{TM}} \mathrm{GO}$ microplate spectrophotometer; Thermo Fisher Scientific, Inc.). Cell viability was calculated by considering the controls as $100 \%$.

Cell lysate preparation. SH-SY5Y cells were harvested by trypsin-EDTA $0.25 \%$ (Thermo Fisher Scientific, Inc.) and collected by centrifugation at $1,000-2,000 \mathrm{x}$ f for $10 \mathrm{~min}$ at $4^{\circ} \mathrm{C}$. Cells were then harvested in ice-cold buffer $(0.05 \mathrm{M}$ potassium phosphate $\mathrm{pH}$ 7.0, $1 \mathrm{mM}$ EDTA) and homogenized by sonication on ice. The solution was centrifuged at $12,000 \mathrm{x} \mathrm{g}$ at $4^{\circ} \mathrm{C}$ for $20 \mathrm{~min}$ to remove cell debris. The supernatant was used for determining the quantity of total protein and for the enzyme activity assay. The protein concentration was determined using the bicinchoninic acid assay kit (Thermo Fisher Scientific, Inc). All spectrophotometric measurements were made using an Epoch microplate spectrophotometer (BioTek Instruments, Inc.).

Catalase (CAT) activity assay. CAT activity in cell lysates was tested by spectrophotometrically monitoring the degradation of hydrogen peroxide $\left(\mathrm{H}_{2} \mathrm{O}_{2}\right)$ for $3 \mathrm{~min}$ at $240 \mathrm{~nm}$ at $25^{\circ} \mathrm{C}$ in the presence of $3 \% \mathrm{H}_{2} \mathrm{O}_{2}$ and $0.1 \mathrm{mM}$ EDTA in $0.05 \mathrm{M}$ potassium phosphate buffer with a pH of 7.0.

SOD activity assay. The SOD assay was performed by quantifying the inhibition of nitro blue tetrazolium (NBT) at $560 \mathrm{~nm}$. The assay mixture $(200 \mu \mathrm{l})$ comprised $0.0033 \mathrm{mM}$ riboflavin, $10 \mathrm{mML}$-methionine, $0.033 \mathrm{mMNBT}$ and $0.66 \mathrm{mM}$ EDTA- $\mathrm{Na}_{2}$ in $0.05 \mathrm{M}$ potassium phosphate buffer ( $\mathrm{pH}$ 7.8). The 96-well plates containing the assay mixture were incubated for $20 \mathrm{~min}$ with $300 \mathrm{nmol} / \mathrm{m}^{2} / \mathrm{sec}$ at $560 \mathrm{~nm}$ excitation at $25^{\circ} \mathrm{C}$. One unit of SOD activity was defined as the amount of protein (in $\mathrm{mg}$ ) causing 50\% inhibition of photoreduction, following which specific enzyme activity was expressed as units/mg protein.

Malondialdehyde (MDA) activity assay. Lipid peroxidation products, including MDA, react with thiobarbituric acid to form a colored product with an absorption maximum of $532 \mathrm{~nm}$. The results are expressed as the molar equivalent of MDA (calculated from the standard curve prepared with tetraethoxypropane) per mg of protein.

$\mathrm{H}_{2} \mathrm{O}_{2}$ activity assay. $\mathrm{H}_{2} \mathrm{O}_{2}$ in cells was quantified using a $\mathrm{H}_{2} \mathrm{O}_{2}$ assay kit (cat no. ab102500; Abcam). In brief, at $24 \mathrm{~h}$ after drug administration, cells were harvested, homogenized and centrifuged. The supernatant was used for the assay. The absorbance was detected at $570 \mathrm{~nm}$ using a microplate reader and the optical density was used for quantification of $\mathrm{H}_{2} \mathrm{O}_{2}$ levels. Distilled water was used as a negative control instead of cell lysate sample.

DAPI staining. At $24 \mathrm{~h}$ after glutamate exposure and/or pre-treatment with VPA, the cells were fixed with methanol/acetic acid at a ratio of 3:1 at room temperature for 

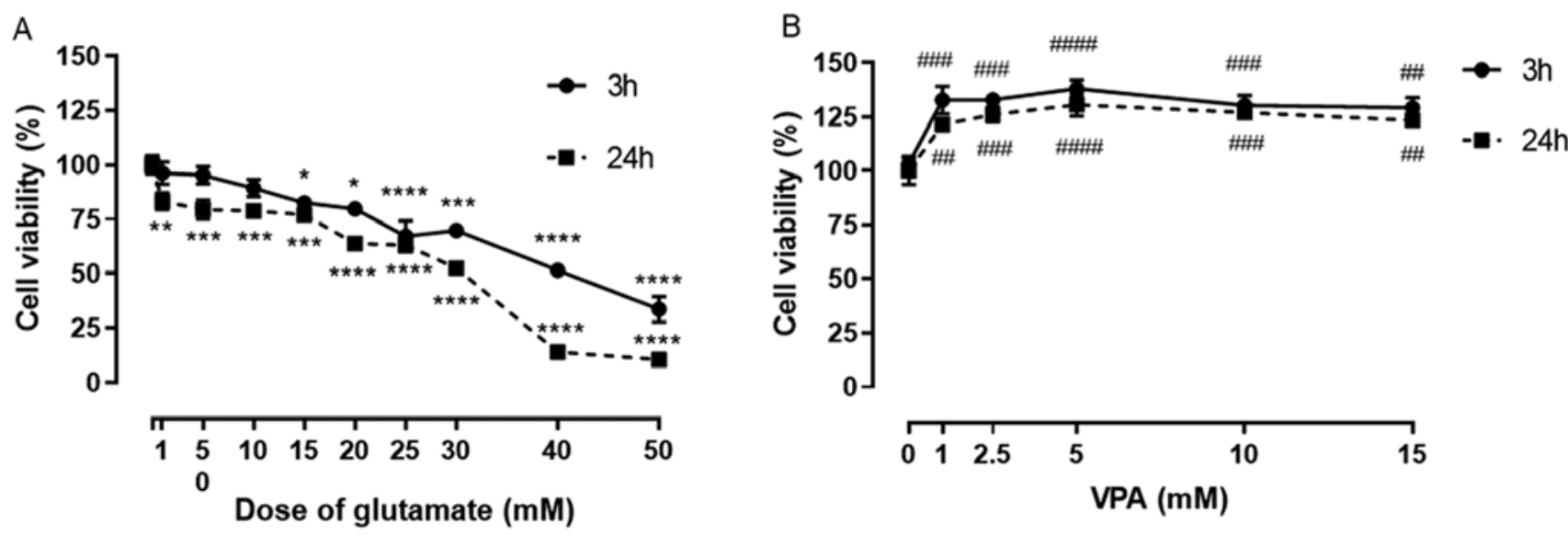

Figure 1. Effect of L-glutamate on SH-SY5Y cell viability. (A) Graph indicating the glutamate-induced dose-dependent decrease in cell viability in SH-SY5Y cells as $\%$ of control. Cells were treated with 9 different concentrations of glutamate $(1,5,10,15,20,25,30,40$ and 50 mM). The cell viability determined after 3 and 24 h of treatment. (B) Graph of the effect of different VPA concentrations (1-15 mM) on cell viability at 3 and 24 h after treatment. Cell viability (\% of control) is expressed as the mean value of four separate experiments ( $\mathrm{n}=8$ per condition). ${ }^{*} \mathrm{P}<0.05,{ }^{* *} \mathrm{P}<0.01,{ }^{* * *} \mathrm{P}<0.001$ and ${ }^{* * * * *} \mathrm{P}<0.0001$ vs. control in $\mathrm{A}$ and

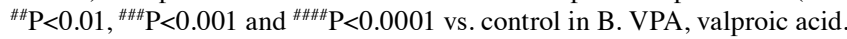

10 min (17). Cells were then washed twice with PBS, stained with DAPI (BioShop Canada, Inc.) for 5 min and examined by fluorescence microscopy (Axio Vert.A1; Carl Zeiss AG). Apoptosis-associated changes in cellular and nuclear morphology were examined and a reduced nuclear size, chromatin condensation, nuclear fragmentation and intense fluorescence were considered to indicate apoptosis. Cells were imaged using Zen 2,6 Blue Edition software (Carl Zeiss, AG).

Statistical analysis. Values are expressed as the mean \pm standard error of the mean and analyzed by one-way analysis of variance, followed by a Bonferroni's multiple-comparisons post-hoc test by Grahpad Prism 8 software (GraphPad Software, Inc.). $\mathrm{P}<0.05$ was considered to indicate a statistically significant difference.

\section{Results}

Dose-response curve of glutamate and VPA. A dose-response curve of glutamate was plotted to determine the toxic concentration of glutamate in SH-SY5Y cells at 3 and at $24 \mathrm{~h}$ of exposure. The decrease in cell viability after exposure to glutamate for $3 \mathrm{~h}$ was not significant at the glutamate concentrations of 1,5 and $10 \mathrm{mM}$. The significant decrease in cell viability started with $15 \mathrm{mM}$ glutamate and decreased progressively with increasing glutamate concentrations. The progressive decline in cell viability was also observed at all concentrations of glutamate $(1-50 \mathrm{mM})$ at $24 \mathrm{~h}$ of exposure (Fig. 1A). The glutamate concentration of $15 \mathrm{mM}$ that caused a $\sim 20 \%$ decrease in cell viability after $24 \mathrm{~h}$ was then used for the subsequent experiments.

VPA treatment alone at concentrations of $1,2.5$, 5,10 and $15 \mathrm{mM}$ significantly increased the cell viability of SH-SY5Y cells, when compared to the control, at 3 and $24 \mathrm{~h}$. A significant increase was observed in cells treated with $1 \mathrm{mM}$ VPA compared with the control ( $130 \%$ of control; Fig. 1B), but no further increases could be observed with further increases in VPA concentration (Fig. 1B).
Effect of VPA pre-treatment on the viability of cells with glutamate-induced excitotoxicity. The effects of different concentrations of VPA $(1,5$ and $10 \mathrm{mM})$ on cell viability, alone and prior to glutamate $(15 \mathrm{mM})$ exposure for 3 and $24 \mathrm{~h}$, are displayed in Fig. 2.

The viability of glutamate-treated cells was significantly increased in the group pre-treated with $1 \mathrm{mM}$ VPA when compared with that of the cells treated with glutamate alone for $3 \mathrm{~h}$. An increase in cell viability at $3 \mathrm{~h}$ was also observed after pre-treatment with 5 and $10 \mathrm{mM}$ VPA; however, these changes were insignificant (Fig. 2A). Of note, pre-treatment with $1 \mathrm{mM}$ VPA significantly increased the viability of cells exposed to glutamate for $24 \mathrm{~h}$ (Fig. 2B). However, 5 and $10 \mathrm{mM}$ VPA concentrations were ineffective in reducing glutamate-induced excitotoxicity; conversely, they further decreased the viability of cells after glutamate exposure for $24 \mathrm{~h}$. Thus, the concentration of $1 \mathrm{mM}$ VPA was used in the further experiments to investigate the potential anti-oxidant effect of VPA in treating glutamate-injured neurons (Fig. 2).

Effects of VPA pre-treatment on $\mathrm{H}_{2} \mathrm{O}_{2}$ and MDA contents in glutamate-induced excitotoxicity. At $24 \mathrm{~h}$ of incubation with $15 \mathrm{mM}$ glutamate, $\mathrm{H}_{2} \mathrm{O}_{2}$ levels were increased as compared with those in the control group $(\mathrm{P}<0.0001)$. VPA treatment alone $(1 \mathrm{mM})$ did not change the $\mathrm{H}_{2} \mathrm{O}_{2}$ levels as compared with those in the control. To explore whether VPA has protective effects against free radical-induced cell injury by scavenging free radicals, the effect of $1 \mathrm{mM}$ VPA on $\mathrm{H}_{2} \mathrm{O}_{2}$ levels was evaluated. Treatment with VPA was indicated to decrease $\mathrm{H}_{2} \mathrm{O}_{2}$ levels in cells exposed to glutamate when compared to treatment with glutamate alone $(\mathrm{P}<0.01)$, but was not able to reduce them to the control levels $(\mathrm{P}<0.01$ vs. control group; Fig. 3A).

MDA levels were significantly increased after a 24-h incubation with glutamate $(\mathrm{P}<0.0001)$. Pre-treatment with VPA $(1 \mathrm{mM})$ reversed the increase of MDA after glutamate exposure, when compared to the control and glutamate alone groups $(\mathrm{P}<0.0001$ vs. control group; $\mathrm{P}<0.0001$ vs. glutamate alone group; Fig. 3B). 
A

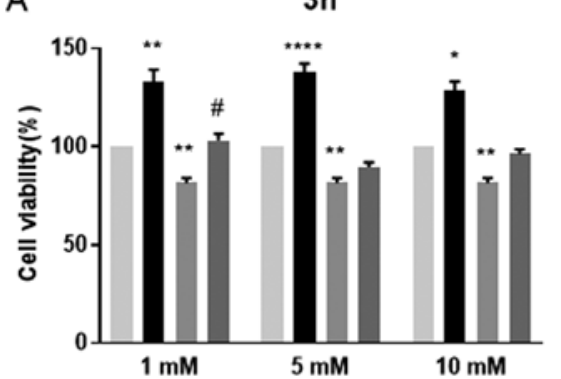

B

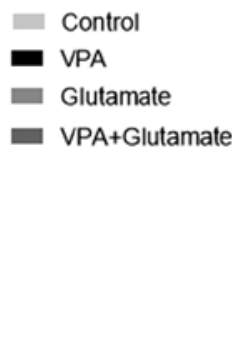

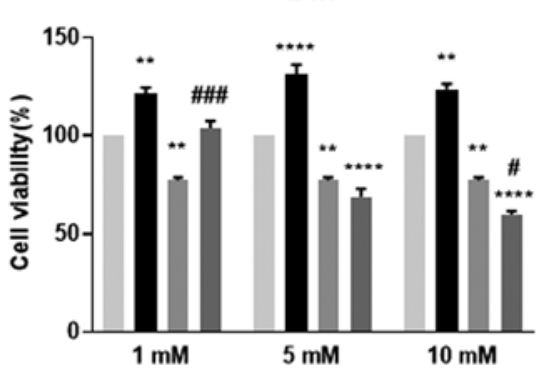

Control

- VPA

- Glutamate

- VPA+Glutamate

Figure 2. Effect of VPA pre-treatment on the viability of SH-SY5Y cells with glutamate-induced excitotoxicity. Viability of SH-SY5Y cells pre-treated with or without VPA $(1,5,10 \mathrm{mM})$ followed by exposure to $15 \mathrm{mM}$ glutamate for $(\mathrm{A}) 3 \mathrm{~h}$ or $(\mathrm{B}) 24 \mathrm{~h}$ to induce excitotoxicity. ${ }^{*} \mathrm{P}<0.05,{ }^{* * *} \mathrm{P}<0.01$ and ${ }^{* * * * *} \mathrm{P}<0.0001$ vs. control group; ${ }^{\#} \mathrm{P}<0.05$ vs. glutamate group in $\mathrm{A} ;{ }^{* *} \mathrm{P}<0.01$ and ${ }^{* * * * *} \mathrm{P}<0.0001$ vs. control group; ${ }^{\#} \mathrm{P}<0.05$ and ${ }^{\# \# \#} \mathrm{P}<0.001$ vs. glutamate group in $\mathrm{B}$. Cell viability (\% of control) is expressed as the mean value of four separate experiments ( $\mathrm{n}=8$ per experiment). VPA, valproic acid.
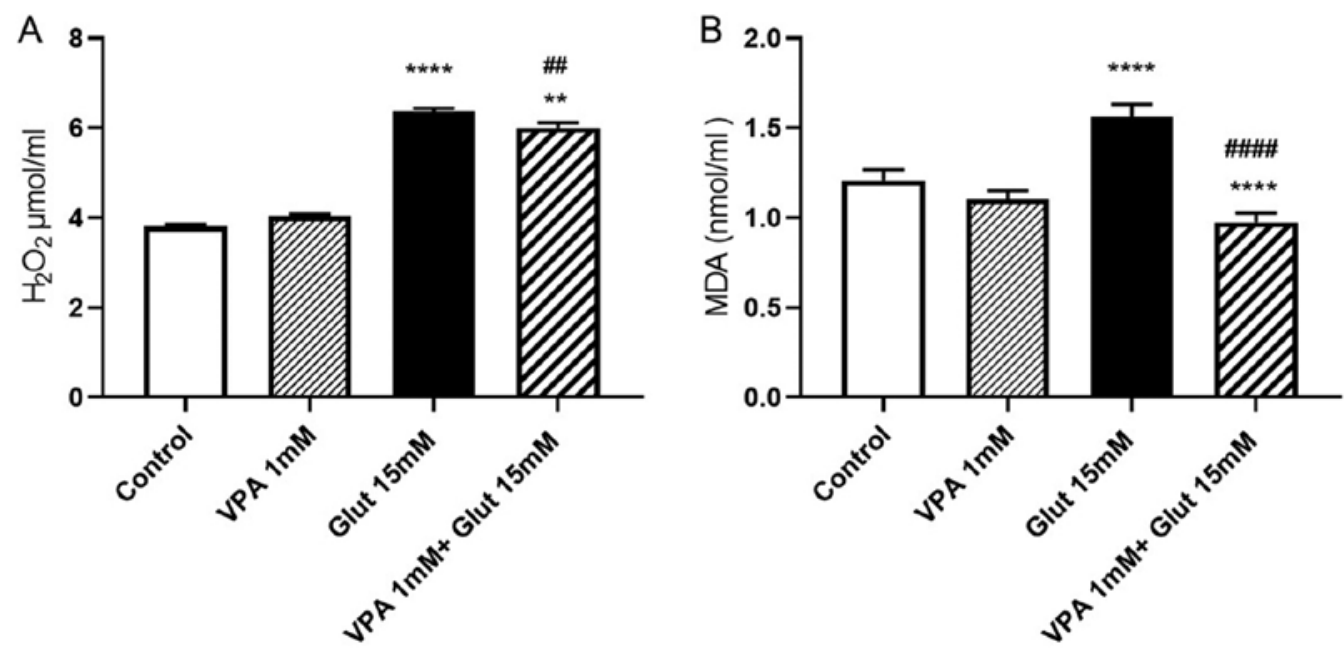

Figure 3. (A) $\mathrm{H}_{2} \mathrm{O}_{2}$ and (B) MDA levels in VPA-pre-treated $\mathrm{SH}-\mathrm{SY} 5 \mathrm{Y}$ cells exposed to glutamate to induce excitotoxicity. ${ }^{* *} \mathrm{P}<0.01$ and ${ }^{* * * *} \mathrm{P}<0.0001$ vs. control group; ${ }^{\# \#} \mathrm{P}<0.01$ vs. glutamate group in $\mathrm{A} .{ }^{* * * *} \mathrm{P}<0.0001$ vs. control group and ${ }^{\# \# \# \#} \mathrm{P}<0.0001$ vs. glutamate group in $\mathrm{B}$. Values are expressed as the mean value of four separate experiments ( $\mathrm{n}=8$ per experiment). $\mathrm{H}_{2} \mathrm{O}_{2}$, hydrogen peroxide; MDA, malondialdehyde; VPA, valproic acid; Glut, glutamate.
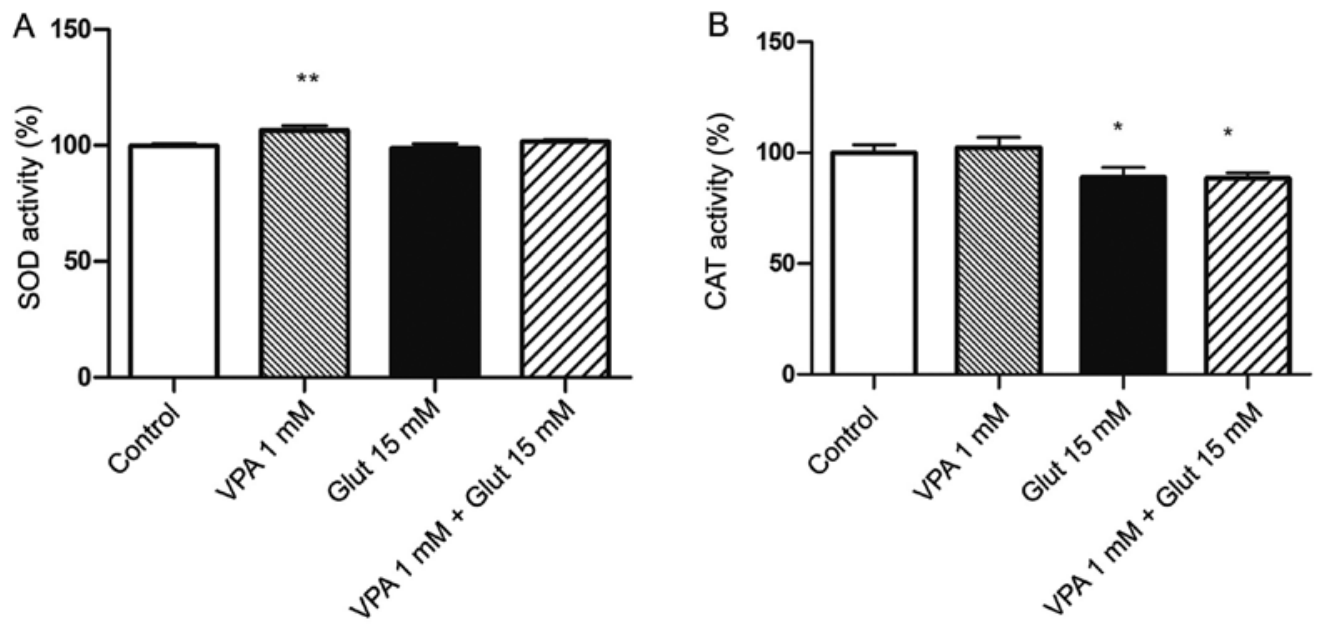

Figure 4. (A) SOD and (B) CAT activity in control cells, VPA-treated cells, cells exposed to glutamate, as well as VPA-pre-treated SH-SY5Y cells exposed to glutamate excitotoxicity. Cell viability was calculated by considering the controls as $100 \%{ }^{* *} \mathrm{P}<0.01$ vs. control in $\mathrm{A} ;{ }^{*} \mathrm{P}<0.05$ vs. control in $\mathrm{B}$. Values are expressed as the mean value of four separate experiments ( $\mathrm{n}=8$ in each experiment). SOD, superoxide dismutase; CAT, catalase; VPA, valproic acid; Glut, glutamate.

Effects of VPA pre-treatment on anti-oxidant enzyme activities in cells with glutamate-induced excitotoxicity. The SOD activity was increased in the $1 \mathrm{mM}$ VPA alone group as compared with that in the control group $(\mathrm{P}<0.01$; Fig. 4A). The SOD activity slightly decreased after glutamate exposure, as compared to the control group, but this 
A

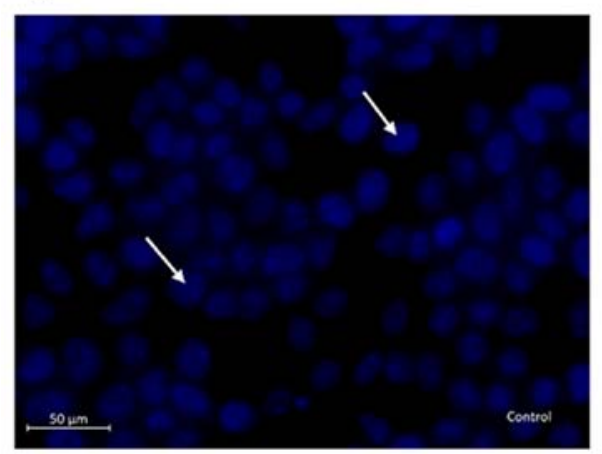

c

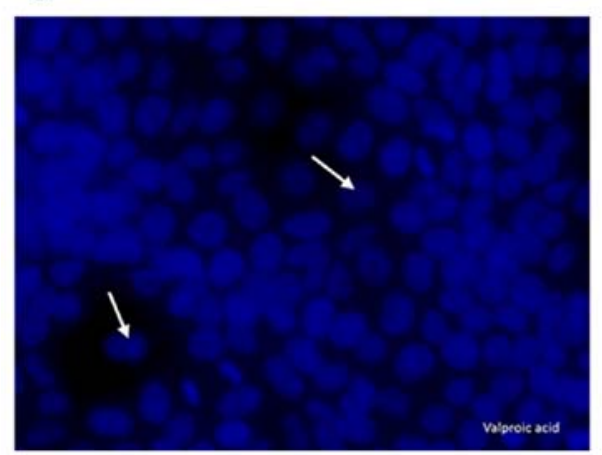

B

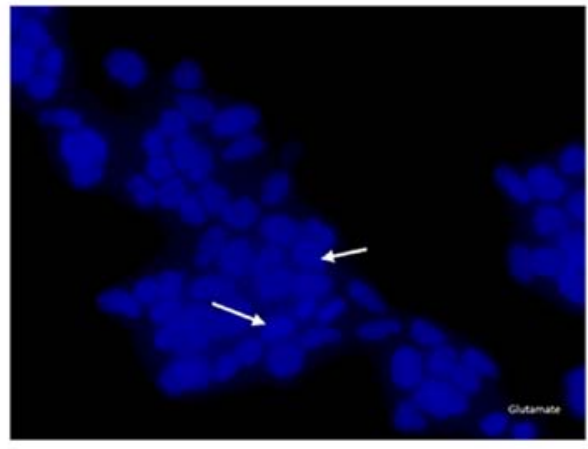

D

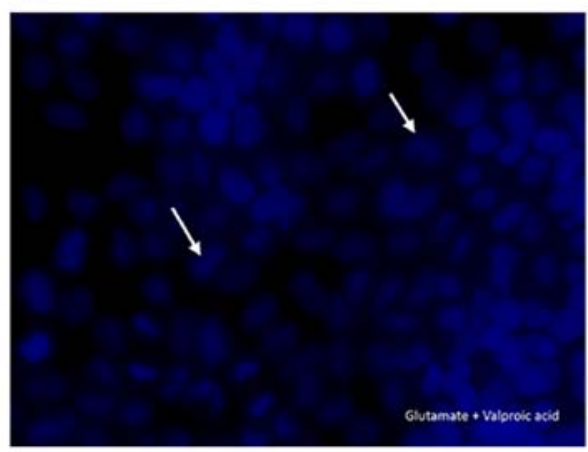

Figure 5. Morphological assessment of the nuclei of SH-SY5Y cells by fluorescence microscopy. (A) Untreated cells were uniformly stained with DAPI. (B) Changes in the cellular and nuclear morphology of glutamate-exposed cells resulted in chromatin condensation and nuclear alterations. Effect of (C) valproic acid alone and (D) pre-treatment prior to glutamate exposure. The nuclei were stained with DAPI. Each photomicrograph was representative of three independent samples. Apoptotic cell nuclei are indicated by white arrows (scale bar, $50 \mu \mathrm{m}$ ).

change was not statistically significant. CAT activity was significantly decreased after exposure to $15 \mathrm{mM}$ glutamate (Fig. 4B). VPA treatment alone slightly increased CAT activity, but the decrease was not significant; furthermore, pre-treatment with VPA had no obvious effect to inhibit the decrease of CAT in glutamate-exposed cells $(\mathrm{P}<0.05$ vs. control; Fig. 4B).

Effects of VPA pre-treatment on nuclear changes in cells with glutamate-induced excitotoxicity. Changes in cellular and nuclear morphology were examined in the control, glutamate-exposed, valproic acid-treated and valproic acid-pre-treated glutamate-exposed cells by DAPI staining (Fig. 5). The control cell nuclei were regular in shape. Morphological characteristics of apoptosis, including reduced nuclear size, chromatin condensation, nuclear fragmentation and intense fluorescence, were observed in glutamate-exposed cells. These changes in nuclear morphology were alleviated by pre-treatment of cells with VPA $(1 \mathrm{mM})$ following exposure to $15 \mathrm{mM}$ glutamate.

\section{Discussion}

The present study focused on an acute excitotoxicity model of cell culture created by short-term exposure to glutamate for up to $24 \mathrm{~h}$. Glutamate exposure for $24 \mathrm{~h}$ was also indicated to cause excitotoxicity in cortical neurons in primary culture (3). In the present study, the effect of VPA on the early stages of acute glutamate-induced neurotoxity, including intracellular ROS, were investigated in SH-SY5Y cells. Exposure to $15 \mathrm{mM}$ glutamate was found to be the least effective compared with other higher doses of glutamate at causing toxicity in SH-SY5Y cells, as indicated by an MTT assay performed after glutamate treatment for $24 \mathrm{~h}$. Among 3 concentrations of VPA (1, 5 and $10 \mathrm{mM})$, only pre-treatment with $1 \mathrm{mM}$ VPA significantly inhibited glutamate-induced toxicity to increase the number of viable cells. Therefore, $15 \mathrm{mM}$ glutamate and $1 \mathrm{mM}$ VPA were used in the subsequent experiments to investigate the potential anti-oxidant effect of VPA to prevent glutamate-induced neuronal injury.

It was observed that acute exposure of glutamate to induce neurotoxicity significantly enhanced $\mathrm{H}_{2} \mathrm{O}_{2}$ levels, suggesting that glutamate-stimulated excitotoxicity in these cells is caused by oxidative damage. Major detrimental forms of ROS include superoxide, hydroxyl radicals and $\mathrm{H}_{2} \mathrm{O}_{2} \cdot \mathrm{H}_{2} \mathrm{O}_{2}$ is one of the key targets for interventions among various ROS products. As $\mathrm{H}_{2} \mathrm{O}_{2}$ is neither a radical nor an ion, it is able to readily cross the cell membrane and affect cellular structures distant from its origin. Oxidative stress lead to protein dysfunction, DNA damage and lipid peroxidation, resulting in cell death in a manner that is dependent on the excessive production of ROS (18). A recent study revealed that 1-50 mM glutamate affected $\mathrm{H}_{2} \mathrm{O}_{2}$ synthesis by brain mitochondria, and this effect was associated with complex II, a source of superoxide formation in mitochondria, and is dependent on the mitochondrial potential (19). Ha et al (20) revealed that, following prolonged exposure to glutamate, extracellular $\mathrm{H}_{2} \mathrm{O}_{2}$ accumulated in a time- and concentration-dependent manner in HT22 cells. $\mathrm{H}_{2} \mathrm{O}_{2}$ formation due to mitochondrial 
superoxide leakage perpetuates oxidative stress in neuronal injury.

In the present study, increased levels of MDA were observed in cells exposed to glutamate. MDA, a product of the breakdown of polyunsaturated fatty acid, commonly known as a marker of oxidative stress, indicates that glutamate excitotoxicity may be associated with oxidative stress. MDA also serves as a convenient indicator of lipid peroxidation (21). In combination, the increased levels of $\mathrm{H}_{2} \mathrm{O}_{2}$ and MDA suggested that glutamate-induced neurotoxicity in SH-SY5Y cells is mediated by oxidative damage. This was consistent with the results of Sun et al (17), who indicated that glutamate exerted its toxicity through oxidative damage in SH-SY5Y cells.

The other result of the present study was that pre-treatment with $1 \mathrm{mM}$ VPA decreased the glutamate-induced increase in $\mathrm{H}_{2} \mathrm{O}_{2}$ and MDA levels, revealing a neuroprotective effect of VPA by decreasing oxidative stress. Previous studies also confirmed that the protective effects of VPA are associated with a reduction of oxidative stress. Chronic treatment with VPA was reported to exert neuroprotective effects against excitotoxicity via inhibition of oxidative damage by decreasing glutamate-induced MDA levels (13). Frey et al (22) also demonstrated that valproate prevented amphetamine-induced lipid peroxidation in the hippocampus and in the prefrontal cortex, revealing the neuroprotective effects of VPA in response to oxidative stress. VPA has also been reported to inhibit the activation of the JNK pathway by decreasing ROS production in a model of spinal cord injury (23). It was reported that treatment with VPA following cerebral ischemia prevented ROS production via the inhibition of HDAC and induction of HSP (24). Silva et al (15) suggested that VPA exerted neuroprotective effects by attenuating the increased HDAC and GSK3 immunoreactivity, which are involved in inflammation and brain function in certain areas of the brain of ischemic animals. Inhibition of these enzymes was demonstrated to reduce ischemic cerebral damage by restoring failing mitochondrial bioenergetics and preventing ROS production $(14,25)$.

The mechanisms through which VPA and other mood stabilizers decrease ROS generation remain to be fully elucidated, but it has been suggested that buffering overloaded intracellular calcium, stabilizing mitochondrial function and increased expression of endoplasmic reticulum stress protein may have a role in it $(13,26,27)$. The inhibition of the GRP78 expression led to an increase in ROS and intracellular calcium levels following oxidative insult (28).

Oxidative stress occurs when cellular anti-oxidant defenses are inadequate to maintain the levels of ROS below the toxic threshold, due to excessive ROS production and/or loss of anti-oxidant defenses $(29,30)$. CAT is one of the most common anti-oxidant enzymes in almost all living organisms that are exposed to oxygen; it catalyzes the reduction of $\mathrm{H}_{2} \mathrm{O}_{2}$ to water and removes organic hydroperoxides (31). SOD is a protective enzyme involved in catalyzing the dismutation of superoxide to less reactive $\mathrm{H}_{2} \mathrm{O}_{2}$ and molecular oxygen $(32,33)$. These anti-oxidants may protect neuronal cells against oxidative damage by $\mathrm{H}_{2} \mathrm{O}_{2}(18,34,35)$. It has been reported that anti-oxidant systems in neurodegenerative disorders have coordinated effects induced by SOD and CAT (36).
In the present study, it was demonstrated that CAT activity is significantly decreased in cells exposed to glutamate. However, VPA did not exert any significant effect on CAT activity in cells cultured with glutamate. These results suggest that CAT activity has a role in glutamate-induced oxidative damage, but VPA does not appear to have a sufficient effect on CAT activity in cells exposed to glutamate. It has also been reported that CAT activity in the brain is significantly lower than that in other organs, including the kidney and liver (37). The low CAT activity may be reduced further by glutamate toxicity, an effect that VPA addition may not be sufficient to alleviate. VPA alone significantly increased the levels of this anti-oxidant enzyme, but exerted no significant effects on glutamate-exposed cells. It was reported that SOD activity may vary among different cell types, e.g. among adult rat brain cells; the specific activity of total SOD has been reported to be $\sim 10$-fold higher in glial cells than in neurons (38).

The results of the present study suggested that VPA exerts a protective effect on glutamate-induced excitotoxicity via decreasing ROS production without influencing anti-oxidant enzymes. Studies have reported controversial results regarding the effect of VPA on anti-oxidant enzymes. It has been indicated that the activity of glutathione S-transferase, glutathione reductase, glutathione peroxidase, SOD and CAT was significantly reduced in the cerebral cortex and cerebellum (39). A study on epileptic children also demonstrated a significant decrease in the anti-oxidant activity of SOD and CAT after VPA treatment (40). Glutathione reductase activity was indicated to be slightly lower in pediatric patients receiving VPA monotherapy and polytherapy, as compared with that in newly diagnosed pediatric patients (41). Other studies have revealed an increase in anti-oxidant enzymes by VPA treatment. It has been suggested that VPA treatment may alter the balance between oxidant and anti-oxidant systems (42). In primary cultured rat cerebral cortical cells, chronic treatment with lithium and valproate at therapeutic concentrations increased the activity of glutathione S-transferase (43).

However, the present study was not without its limitations. The potential contamination of the cells was not investigated, but the present results are in line with the literature and they will be confirmed in vivo or in primary cultured cells in future projects.

In conclusion, the present study demonstrated that pre-treatment with $1 \mathrm{mM}$ VPA effectively prevented the decline in neuronal cell viability induced by glutamate exposure in SH-SY5Y cells via decreasing oxidative stress.

\section{Acknowledgements}

The authors would like to thank Miss Ilgın Akpınar from İstanbul University, Institution of Science, Department of Botany (Istanbul, Turkey) and Dr İbrahim Akalın from İstanbul Medeniyet University, Department of Medical Genetics (Istanbul, Turkey) for their technical contributions.

\section{Funding}

No funding was received. 


\section{Availability of data and materials}

The datasets used and/or analyzed during the current study are available from the corresponding author on reasonable request.

\section{Authors' contributions}

BTB designed the study. BTB, EO and GA performed the experiments and analyzed and interpreted the data. All authors contributed to the writing of the manuscript and read and approved the final manuscript.

\section{Ethics approval and consent to participate}

Not applicable.

\section{Patient consent for publication}

Not applicable.

\section{Competing interests}

All authors declare that they have no competing interests.

\section{References}

1. Wang R and Reddy PH: Role of Glutamate and NMDA receptors in Alzheimer's disease. J Alzheimers Dis 57: 1041-1048, 2017.

2. Bleich S, Römer K, Wiltfang J and Kornhuber J: Glutamate and the glutamate receptor system: A target for drug action. Int J Geriatr Psychiatry 18 (Suppl 1): S33-S40, 2003.

3. Schubert D and Piasecki D: Oxidative glutamate toxicity can be a component of the excitotoxicity cascade. J Neurosci 21 : 7455-7462, 2001.

4. Kritis AA, Stamoula EG, Paniskaki KA and Vavilis TD Researching glutamate-induced cytotoxicity in different cell lines: A comparative/collective analysis/study. Front Cell Neurosci 9: 91, 2015.

5. Andersen JK: Oxidative stress in neurodegeneration: Cause or consequence? Nat Med 10 (Supp 1): S18-S25, 2004.

6. Venkateshappa C, Harish G, Mythri RB, Mahadevan A, Bharath MM and Shankar SK: Increased oxidative damage and decreased antioxidant function in aging human substantia nigra compared to striatum: Implications for Parkinson's disease. Neurochem Res 37: 358-369, 2012.

7. Kumar A, Singh RL and Babu GN: Cell death mechanisms in the early stages of acute glutamate neurotoxicity. Neurosci Res 66: 271-278, 2010

8. Floyd RA: Antioxidants, oxidative stress, and degenerative neurological disorders. Proc Soc Exp Biol Med 222: 236-245, 1999.

9. Calabrese V, Scapagnini G, Giuffrida Stella AM, Bates TE and Clark JB: Mitochondrial involvement in brain function and dysfunction: Relevance to aging, neurodegenerative disorders and longevity. Neurochem Res 26: 739-764, 2001.

10. Atlante A, Calissano P, Bobba A, Giannattasio S, Marra E and Passarella S: Glutamate neurotoxicity, oxidative stress and mitochondria. FEBS Lett 497: 1-5, 2001.

11. Aoyama K and Nakaki T: Inhibition of GTRAP3-18 may increase neuroprotective glutathione (GSH) synthesis. Int J Mol Sci 13: 12017-12035, 2012.

12. Vajda FJ: Valproate and neuroprotection. J Clin Neurosci 9: $508-514,2002$

13. Shao L, Young LT and Wang JF: Chronic treatment with mood stabilizers lithium and valproate prevents excitotoxicity by inhibiting oxidative stress in rat cerebral cortical cells. Biol Psychiatry 58: 879-884, 2005.

14. Pang T, Wang YJ, Gao YX, Xu Y, Li Q, Zhou YB, Xu L, Huang ZJ, Liao H, Zhang LY, et al: A novel GSK-3 $\beta$ inhibitor YQ138 prevents neuronal injury induced by glutamate and brain ischemia through activation of the Nrf2 signaling pathway. Acta Pharmacol Sin 37: 741-752, 2016.
15. Silva MR, Correia AO, Dos Santos GCA, Parente LLT, de Siqueira KP, Lima DGS, Moura JA, da Silva Ribeiro AE, Costa RO, Lucetti DL, et al: Neuroprotective effects of valproic acid on brain ischemia are related to its HDAC and GSK3 inhibitions. Pharmacol Biochem Behav 167: 17-28, 2018.

16. Chen S, Wu H, Klebe D, Hong Y and Zhang J: Valproic acid: A new candidate of therapeutic application for the acute central nervous system injuries. Neurochem Res 39: 1621-1633, 2014.

17. Sun ZW, Zhang L, Zhu SJ, Chen WC and Mei B: Excitotoxicity effects of glutamate on human neuroblastoma SH-SY5Y cells via oxidative damage. Neurosci Bull 26: 8-16, 2010.

18. Uttara B, Singh AV,Zamboni P and Mahajan RT: Oxidative stress and neurodegenerative diseases: A review of upstream and downstream antioxidant therapeutic options. Curr Neuropharmacol 7: 65-74, 2009.

19. Lobysheva NV, Selin AA, Vangeli IM, Byvshev IM, Yaguzhinsky LS and Nartsissov YR: Glutamate induces $\mathrm{H} 2 \mathrm{O} 2$ synthesis in nonsynaptic brain mitochondria. Free Radic Biol Med 65: 428-435, 2013

20. Ha JS, Lim HM and Park SS: Extracellular hydrogen peroxide contributes to oxidative glutamate toxicity. Brain Res 1359: 291-297, 2010.

21. Maes M, Mihaylova I, Kubera M, Uytterhoeven M, Vrydags N and Bosmans E: Increased plasma peroxides and serum oxidized low density lipoprotein antibodies in major depression: Markers that further explain the higher incidence of neurodegeneration and coronary artery disease. J Affect Disord 125: 287-294, 2010.

22. Frey BN, Valvassori SS, Réus GZ, Martins MR, Petronilho FC, Bardini K, Dal-Pizzol F, Kapczinski F and Quevedo J: Effects of lithium and valproate on amphetamine-induced oxidative stress generation in an animal model of mania. J Psychiatry Neurosci 31: 326-332, 2006.

23. Lee JY, Maeng S, Kang SR, Choi HY, Oh TH, Ju BG and Yune TY: Valproic acid protects motor neuron death by inhibiting oxidative stress and endoplasmic reticulum stress-mediated cytochrome $\mathrm{C}$ release after spinal cord injury. J Neurotrauma 31: 582-594, 2014.

24. Xuan A, Long D, Li J, Ji W, Hong L, Zhang M and Zhang W: Neuroprotective effects of valproic acid following transient global ischemia in rats. Life Sci 90: 463-468, 2012.

25. Valerio A, Bertolotti P, Delbarba A, Perego C, Dossena M, Ragni M, Spano P, Carruba MO, De Simoni MG and Nisoli E: Glycogen synthase kinase-3 inhibition reduces ischemic cerebral damage, restores impaired mitochondrial biogenesis and prevents ROS production. J Neurochem 116: 1148-1159, 2011.

26. Wang JF, Azzam JE and Young LT: Valproate inhibits oxidative damage to lipid and protein in primary cultured rat cerebrocortical cells. Neuroscience 116: 485-489, 2003.

27. Brookes PS, Yoon Y, Robotham JL, Anders MW and Sheu SS: Calcium, ATP, and ROS: A mitochondrial love-hate triangle. Am J Physiol Cell Physiol 287: C817-C833, 2004.

28. Liu H, Bowes RC, van de Water B, Sillence C, Nagelkerke JF and Stevens JL: Endoplasmic reticulum chaperones GRP78 and calreticulin prevent oxidative stress, $\mathrm{Ca} 2+$ disturbances, and cell death in renal epithelial cells. J Biol Chem 272: 21751-21759, 1997.

29. Halliwell B: Free radicals and antioxidants-quo vadis? Trends Pharmacol Sci 32: 125-130, 2011.

30. Duračková Z: Free radicals and antioxidants for Non-experts. In: Systems Biology of Free Radicals and Antioxidants. Laher I (ed). Springer, Berlin, Heidelberg, pp3-38, 2014.

31. Jornada LK, Valvassori SS, Steckert AV, Moretti M, Mina F, Ferreira CL, Arent CO, Dal-Pizzol F and Quevedo J: Lithium and valproate modulate antioxidant enzymes and prevent ouabain-induced oxidative damage in an animal model of mania. J Psychiatr Res 45: 162-168, 2011.

32. Dringen R, Pawlowski PG and Hirrlinger J: Peroxide detoxification by brain cells. J Neurosci Res 79: 157-165, 2005.

33. Yasui $\mathrm{K}$ and Baba A: Therapeutic potential of superoxide dismutase (SOD) for resolution of inflammation. Inflamm Res 55: 359-363, 2006.

34. Chadwick W, Zhou Y, Park SS, Wang L, Mitchell N, Stone MD, Becker KG, Martin B and Maudsley S: Minimal peroxide exposure of neuronal cells induces multifaceted adaptive responses. PLoS One 5: e14352, 2010.

35. Halliwell B: Oxidative stress and neurodegeneration: Where are we now? J Neurochem 97: 1634-1658, 2006.

36. Kapczinski F, Frey BN, Andreazza AC, Kauer-Sant'Anna M, Cunha $\mathrm{AB}$ and Post RM: Increased oxidative stress as a mechanism for decreased BDNF levels in acute manic episodes. $\mathrm{Br}$ J Psychiatry 30: 243-245, 2008. 
37. Wilson JX: Antioxidant defense of the brain: A role for astrocytes. Can J Physiol Pharmacol 75: 1149-1163, 1997.

38. Savolainen $\mathrm{H}$ : Superoxide dismutase and glutathione peroxidase activities in rat brain. Res Commun Chem Pathol Pharmacol 21: 173-176, 1978.

39. Chaudhary $S$ and Parvez S: An in vitro approach to assess the neurotoxicity of valproic acid-induced oxidative stress in cerebellum and cerebral cortex of young rats. Neuroscience 225: 258-268, 2012.

40. Zhang Y, Wu JY, Weng LH, Li XX, Yu LJ and Xu Y: Valproic acid protects against MPP+-mediated neurotoxicity in SH-SY5Y Cells through autophagy. Neurosci Lett 638: 60-68, 2017.

41. Sołowiej E and Sobaniec W: The effect of antiepileptic drug therapy on antioxidant enzyme activity and serum lipid peroxidation in young patients with epilepsy. Neurol Neurochir Pol 37: 991-1003, 2003 (In Polish).
42. Yis U, Seckin E, Kurul SH, Kuralay F and Dirik E: Effects of epilepsy and valproic acid on oxidant status in children with idiopathic epilepsy. Epilepsy Res 84: 232-237, 2009.

43. Wang JF, Shao L, Sun X and Young LT: Glutathione $\mathrm{S}$-transferase is a novel target for mood stabilizing drugs in primary cultured neurons. J Neurochem 88: 1477-1484, 2004.

This work is licensed under a Creative Commons Attribution-NonCommercial-NoDerivatives 4.0 International (CC BY-NC-ND 4.0) License. 